\title{
A field and laboratory evaluation of a commercial ELISA for the detection of Giardia coproantigens in humans and dogs.
}

R. M. Hopkins ${ }^{1}$, P. Deplazes ${ }^{2}$, B. P. Meloni ${ }^{1}$, J. A. Reynoldson ${ }^{1}$ and R. C. A. Thompson ${ }^{1}{ }^{1}$ Institute for Molecular Genetics and Animal Disease and School of Veterinary Studies, Murdoch University, Murdoch, Western Australia, Australia; ${ }^{2}$ Institute of Parasitology, University of Zürich, Zürich, Switzerland

\begin{abstract}
A capture enzyme linked immunosorbent assay (CELISA ${ }^{(3)}$ ) was evaluated for its ability to detect Giardia coproantigens in the faeces of humans and dogs in the Perth metropolitan area and Aboriginal communities in Fitzroy Crossing, Western Australia. Using zinc sulphate flotation and light microscopy, Giardia cysts and/or trophozoites were observed in 8 of $57(14 \%)$ human stool samples from Perth and 21 of $55(38 \%)$ stool samples from Fitzroy Crossing, after 2 separate examinations. Analysis of diagnostic sensitivity using the ELISA revealed that coproantigens were detected in all 29 human samples (100\%) in which Giardia cysts and/or trophozoites were also present. Coproantigens were detected in one further sample from Perth and in 3 samples from Fitzroy Crossing in which no Giardia cyst or trophozoite was observed. The specificity of the test, as defined using Fitzroy Crossing samples free from Giardia, was $91 \%$. The assay did not crossreact with Giardia-free stool samples containing Hymenolepis nana, Entamoeba coli, E. hartmanni, Chilomastix mesnili or Ancylostoma duodenale. Giardia cysts and/or trophozoites were also observed in 11 of 32 dog faecal samples (34\%) in Perth and 11 of 29 dog samples (38\%) in Fitzroy Crossing, after one zinc sulphate examination. The sensitivity of the ELISA for dogs was $64 \%$ and $55 \%$ for Perth and Fitzroy Crossing specimens respectively. The specificity was $95 \%$ when Fitzroy Crossing samples were used. Other parasites observed in Giardia-free faecal samples from dogs which did not produce a positive reaction with the kit were Ancylostoma caninum, Sarcocystis sp. and Isospora sp. The assay was tested under field conditions, in Fitzroy Crossing, where the results were read visually and were shown to correlate well with results obtained using spectrophotometry. Giardia coproantigens present in human stools remained detectable by the ELISA even after storage untreated at $25^{\circ} \mathrm{C}$ for $8 \mathrm{~d}$.
\end{abstract}

\section{Introduction}

Giardia duodenalis is the most commonly reported intestinal protozoan infection of man, in the USA, UK and Australia (BOREHAM, 1981; MEYER, 1985) and particularly in under-privileged groups (MELONI et al., 1988; ISLAM, 1990). High prevalence rates of Giardia infections have also been reported in domestic animals, including dogs and cats (SWAN \& THOMPSON, 1986; CASTOR \& LINDQVIST, 1990). Although the relationship between Giardia in humans and animals is unresolved, the potential for zoonotic transfer of the parasite still exists. This is particularly apparent in areas where people and dogs live in close proximity to each other, such as in Aboriginal communities in Australia (MELONI et al., 1988; THOMP. SON, 1992)

As the extent of morbidity caused by Giardia and its potential for zoonotic transfer have become better understood increasing importance has been placed on the methods of parasite detection. Traditionally, Giardia diagnosis has been performed using concentration techniques and light microscopy. However, the sensitivity of these techniques can vary between 50 and $98 \%$, due largely to the intermittent nature of cyst excretion (BURKE, 1975; WOLFE, 1978). In recent years the sensitivity of Giardia diagnosis has been greatly enhanced through the use of immunological assays. These include enzyme-linked immunosorbent assay (ELISA) and dotELISA to detect Giardia coproantigens in faeces (UNGAR et al., 1984; JANOFF et al., 1989; VINAYAK et al., 1991). Despite the potential for Giardia coproantigen detection in humans, very few commercial diagnostic kits are available for routine diagnostic use (Rosoff et al., 1989). Furthermore, there has been only limited application of these assays for the diagnosis of intestinal parasites in animals, it being confined to cestode parasites in dogs (DEPLAZES et al., 1992) and Giardia coproantigens in calves (TAMINELLI et al., 1989).

In this study we report on the field evaluation of a commercial capture ELISA for Giardia diagnosis in humans and dogs in a remote Aboriginal community in the north of Western Australia. Such a diagnostic tool has important implications for detection of Giardia in remote

Address for correspondence: Dr R. C. A. Thompson, Institute for Molecular Genetics and Animal Disease and School of Veterinary Studies, Murdoch University, Murdoch, 6150, Western Australia, Australia. communities where the prevalence of Giardia is high (MELONI et al., 1988) but access to methods of parasite diagnosis are difficult and expensive.

\section{Materials and Methods}

Collection of samples

Stool samples were collected from the following sources.

(i) 55 stool samples were collected when passed from Aboriginal children (aged 1-8 years) in Fitzroy Crossing in the Kimberly region of Western Australia, and examined within $24-36 \mathrm{~h}$.

(ii) 29 faecal samples were obtained from the rectum of 20 dogs after necropsy in Aboriginal communities in Fitzroy Crossing and from fresh faeces $(n=9)$ located around the Aboriginal campsites.

(iii) 57 stool samples were obtained from children less than 10 years of age, all of whom were living in Perth. All specimens were received from a clinical laboratory (Clinipath Diagnostics) where they had been kept at $4^{\circ} \mathrm{C}$ for 2-3 d before being sent to Murdoch University.

(iv) 32 faecal samples were collected within $24 \mathrm{~h}$ from dogs in the Murdoch University animal house $(n=13)$ or veterinary clinic $(n=19)$. All dogs originated from residential areas in Perth.

\section{Faecal examination}

All stool samples were kept at $4^{\circ} \mathrm{C}$ for $1-48$ h before examination by microscopy. Human samples were examined for the presence of intestinal parasites twice and dog samples examined once, using $\mathrm{ZnSO}_{4}$ concentration. This involved mixing $1 \mathrm{~g}$ of faeces with $9 \mathrm{ml}$ of distilled $\mathrm{H}_{2} \mathrm{O}$ in a $10 \mathrm{ml}$ plastic centrifuge tube (Disposable Products, Australia). The tube was centrifuged at $600 \mathrm{~g}$ for $3 \mathrm{~min}$, the pellet resuspended in $9 \mathrm{ml}$ of $\mathrm{ZnSO}_{4}$ $(33.1 \mathrm{mg} / \mathrm{ml}$ ), and centrifuged again at $500 \mathrm{~g}$ for $3 \mathrm{~min}$. A small volume of faecal suspension was carefully removed from the surface of the liquid using a wire loop and placed on a microscope slide. This was repeated 3 times before a drop of Sargeaunt's stain was mixed with the sample, a cover slip added and the slide examined for parasites for 5-10 min at $100 \times$ magnification.

\section{Processing of samples for ELISA}

Immediately after samples were received in the labora- 
tory, approximately $1 \mathrm{~g}$ of faeces from each specimen was mixed with $9 \mathrm{ml}$ of $10 \%$ formalin in phosphate-buf fered saline (PBS) and then kept at $4^{\circ} \mathrm{C}$ overnight. Samples were centrifuged at $600 \mathrm{~g}$ for $5 \mathrm{~min}$, the supernatants collected and then frozen at $-20^{\circ} \mathrm{C}$ until use.

\section{ELISA procedure}

Coproantigen detection was performed with the CELISA ${ }^{\circledR}$ detection kit (Cellabs, Brookvale, NSW, Australia) and is summarized as follows; $100 \mu l$ faecal sample supernatant were dispensed in duplicate to wells of flatbottomed CELISA strips, pre-coated with mouse antiGiardia monoclonal antibodies which recognize $30 \mathrm{kDa}$ and $65 \mathrm{kDa}$ Giardia antigens. After $10 \mathrm{~min}$ incubation at $37^{\circ} \mathrm{C}$ (in the field at ambient temperatures of $25^{\circ} \mathrm{C}-30^{\circ} \mathrm{C}$ ) wells were washed 4 times with PBS-0.05\% Tween-20 and then incubated with polyclonal rabbit anti-Giardia antibodies (diluted 1:200 in PBS-0.05\% Tween-20) for $1 \mathrm{~h}$ at $37^{\circ} \mathrm{C}$. Wells were washed a further 4 times and then incubated at $37^{\circ} \mathrm{C}$ for $1 \mathrm{~h}$ with goat anti-rabbit immunoglobin $\mathrm{G}$ antibodics conjugated with horse radish peroxidase (diluted 1:100 in PBS-0.05\% Tween-20). After a further 4 washes the wells were incubated at room temperature with tetramethylbenzidine substrate to develop a blue colour. The reaction was stopped after $20 \mathrm{~min}$ using $1 \mathrm{M}$ phosphoric acid. Results were read either visually or by using an ELISA plate reader (Bio$\left.\operatorname{rad}^{\circledR}\right)$ at $450 \mathrm{~nm}\left(A_{450} \mathrm{~nm}\right)$.

\section{Test interpretation}

For interpretation of ELISA results using spectrophotometry, a cut-off value was determined by calculating the mean A $450 \mathrm{~nm}$ value plus 3 standard deviations of Giardia cyst/trophozoite negative samples, collected from humans and dogs in Perth.

In order to discriminate visually between a positive

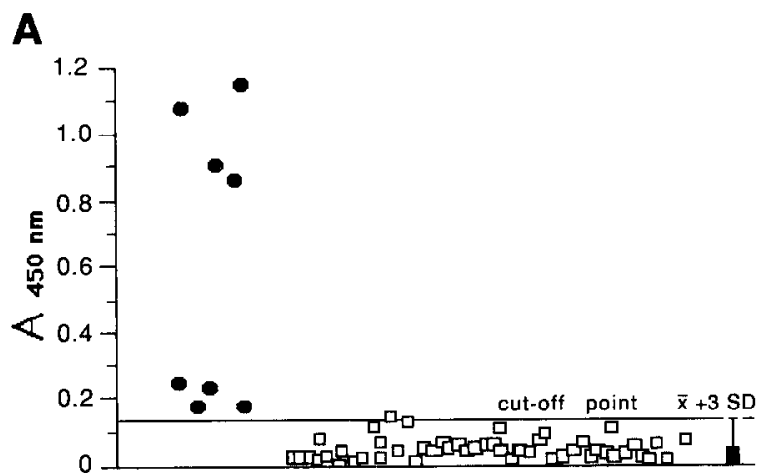

B

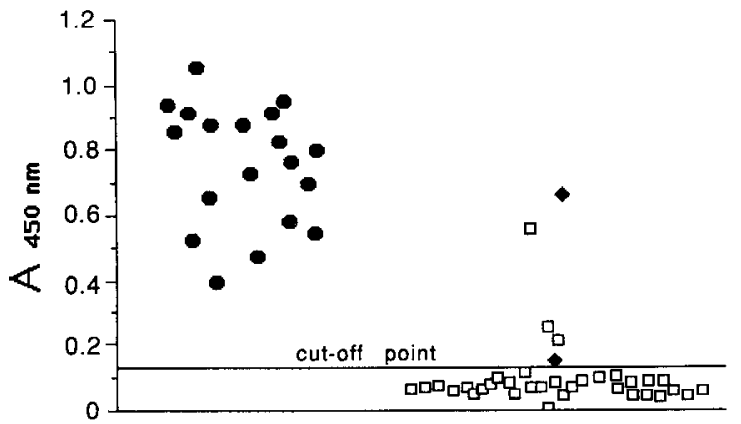

Fig. 1. Diagnostic sensitivity and specificity of the CELISA for human stool samples in Australia. A, 57 samples from Perth and B, 55 samples from Fitzroy Crossing. Giardia positive samples after first and second $\mathrm{ZnSO}_{4}$ flotation; Giardia positive samples only after second $\mathrm{ZnSO}_{4}$ flotation; $\square$ Giardia negative samples after two $\mathrm{ZnSO}_{4}$ flotations. The cut-off point was determined by calculating the mean absorbence value $\left(A_{450 \mathrm{~nm}}\right)$ plus 3 standard deviations $(\bar{x}+3 \mathrm{sD})$ of 49 human samples from Perth which were negative for Giardia after two $\mathrm{ZnSO}_{4}$ flotations. and negative colour reaction, 2 negative samples with A $450 \mathrm{~nm}$ values equal to the mean value of the negative population of Perth, a Giardia positive sample with weak colour reactivity just above the cut-off value, and the positive control from the CELISA kit were used on each plate as standards.

\section{Results}

Sensitivity and specificity of ELISA for human samples

The results of the test evaluation for human stool samples are presented in Fig. 1. Using $\mathrm{ZnSO}_{4}$ concentration, Giardia was detected in 8 of 57 samples $(14 \%)$ from Perth and 21 of 55 samples (38\%) from Fitzroy Crossing. The sensitivity of the ELISA, relative to $\mathrm{ZnSO}_{4}$ flotation, was $100 \%$ for all cyst and/or trophozoite positive samples from both locations. Giardia coproantigens were detected in one sample from Perth and 3 samples from Fitzroy Crossing, which were negative for Giardia by $\mathrm{ZnSO}_{4}$, was $91 \%$.

Other parasites found in human stool samples in which no Giardia was observed were Hymenolepis nana (7), Entamoeba coli (6), E. hartmanni, Chilomastix mesnili (1) and Ancylostoma duodenale (1). None of these samples showed a positive reaction in the CELISA.

Visual results obtained under field conditions using samples from Fitzroy Crossing demonstrated a sensitivity of $95 \%$ and a specificity of $91 \%$.

Sensitivity and specificity of ELISA for dog samples

Absorbence values for dog specimens from Perth and Fitzroy Crossing are shown in Fig. 2. $\mathrm{ZnSO}_{4}$ flotation detected Giardia in 11 of 32 samples from Perth (34\%). The sensitivity of the ELISA for these samples was $64 \%$. Eleven of the 29 Fitzroy Crossing samples (38\%) were positive for Giardia after a single $\mathrm{ZnSO}_{4}$ flotation. The ELISA detected coproantigens in 6 of these 11 positive samples (sensitivity $=55 \%$ ). One sample negative for Giardia by $\mathrm{ZnSO}_{4}$ flotation was found to be positive by ELISA, giving a specificity of $95 \%$. Other parasites observed in dog faeces in which Giardia was not present were Ancylostoma caninum (14), Sarcocystis sp. (7) and Isospora sp. (2). All of these samples were negative for
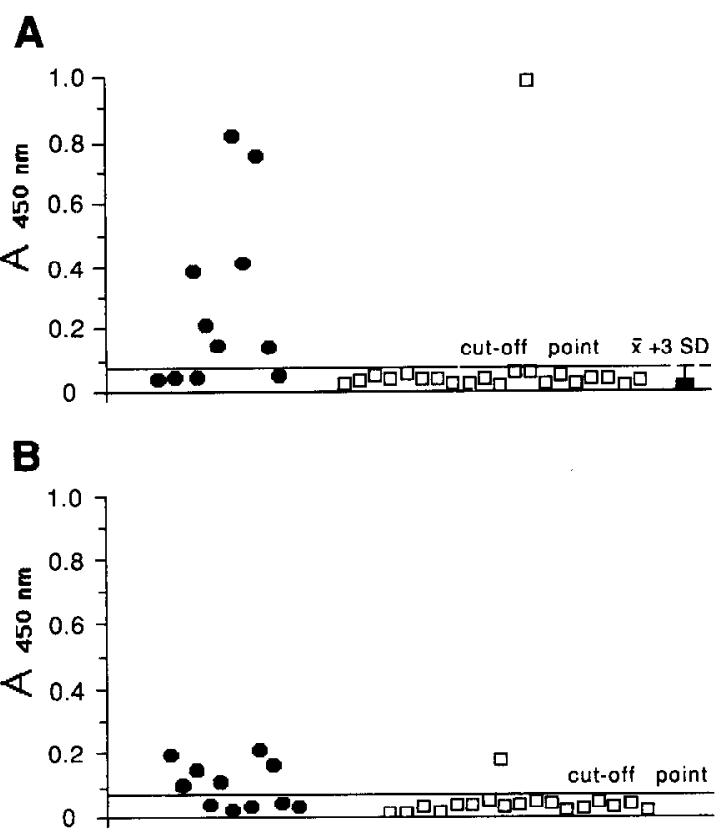

Fig. 2. Diagnostic sensitivity and specificity of the CELISA for faecal samples from dogs in Australia. A, 32 samples from Perth and B, 29 samples from Fitzroy Crossing. Giardia positive samples after $\mathrm{ZnSO}_{4}$ flotation; $\square$ Giardia negative samples after $\mathrm{ZnSO}_{4}$ flotation. The cut-off point was determined by calculating the mean absorbence value $\left(A_{450} \mathrm{~nm}\right)$ plus 3 standard deviations $(\bar{x}+3 \mathrm{sD})$ of 20 faecal samples from dogs in Perth which were negative for Giardia after $\mathrm{ZnSO}_{4}$ flotation (one sample with a strong positive reaction in the CELISA was excluded). 
Giardia in the ELISA.

Under field conditions, visual analysis of dog faecal samples from Fitzroy Crossing resulted in a sensitivity of $64 \%$ and a specificity of $89 \%$.

Reproducibility of the CELISA and stability of Giardia coproantigens

Overall, $4 \%$ of human and $7 \%$ of dog samples were repeated using the ELISA. This occurred when the variation in absorbence between duplicate wells with at least one positive reaction exceeded $20 \%$.

The stability of coproantigens in human stools was tested using 2 coproantigen positive samples. After $8 \mathrm{~d}$ storage at room temperature the $\mathrm{A} 450 \mathrm{~nm}$ values for both samples had decreased by $10 \%$, but still remained positive. One human specimen which was negative for coproantigens remained negative over the same exposure time.

\section{Discussion}

Our evaluation of the ELISA showed that, for diagnosing Giardia infection in human stool samples, the kit was more sensitive than one $\mathrm{ZnSO}_{4}$ flotation and at least as sensitive as two $\mathrm{ZnSO}_{4}$ flotations. Coproantigens were detected in all human stool samples which contained either cysts or trophozoites. The intensity of colour reaction produced with the kit did not correlate with the numbers of cysts or trophozoites present (data not shown), suggesting that free coproantigens were being detected. The ELISA also gave a positive reaction with 4 human stool samples in which no Giardia organism was observed. While it is difficult to prove that these samples represented true Giardia positives, there is some evidence to indicate that this was the case. It is reasonable to assume that, because only one faecal specimen was examined from each person, the results obtained using $\mathrm{ZnSO}_{4}$ flotation represented an underestimate of the true number of Giardia-infected individuals. Since Fitzroy Crossing is known to be more highly endemic for Giardia than Perth (MELONI $e t$ al., 1988), a larger number of infected people would be expected to remain undetected in the former population, when diagnosis was attempted using $\mathrm{ZnSO}_{4}$ flotation. The ability of the ELISA to detect 3 samples in Fitzroy Crossing in which no Giardia cyst or trophozoite was observed, as opposed to only one in Perth, is in concordance with this. Other studies have shown that ELISAs can detect Giardia coproantigens during the pre-patent period of infection and also when cysts are not present in faeces of human individuals known to be infected with Giardia (NASH et al., 1987; TAMINELLI et al., 1989).

In contrast to the high diagnostic sensitivity $(100 \%)$ observed in our study for human stool samples, the ELISA recognized only $55-64 \%$ of dog samples found to contain Giardia by $\mathrm{ZnSO}_{4}$ flotation. In addition, as with human samples, the number of Giardia parasites present in dog faeces did not correlate with the relative coproantigen concentration. This reduced level of sensitivity may have been due to dogs being infected with isolates of Giardia that were antigenically undetectable by the ELISA. Dog isolates are known to exhibit different isoenzymc profiles from human isolates (MELONI $e t$ al., 1989) and repeated attempts to culture Giardia isolated from dogs in our laboratory have failed. It is also possible that Giardia coproantigens, either free from or attached to the surface of cysts and trophozoites, are more readily broken down by the enzyme components of the dog digestive tract than in humans. Studies are currently under way to determine the cause of the low levels of sensitivity.

The excellent correlation observed between visual and spectrophotometric analyses shows that the ELISA is able to perform very effectively under field conditions. The robust nature of the kit was also demonstrated by the fact that it was used in environments quite distinct from those found in the laboratory and that it required only a minimal amount of scientific equipment to operate. These attributes, together with the fact that the kit is able to process large numbers of samples at any one time, means the ELISA could represent a considerable saving in the time and expertise required to diagnose Giardia in remote areas. This may be of benefit to those people who live in regions where the prevalence and impact of Giardia infections are felt much more greatly than by those living in cities.

\section{Acknowledgements}

We acknowledge the assistance of the community health nurses in Fitzroy Crossing, the Derby shire ranger, and Clinipath Diagnostics for their help in obtaining human and animal samples. We also thank Dr Jaeil Lee for help in parasite diagnosis and Cellabs for supplying the CELISA ${ }^{\circledR}$. This research was partially funded by the National Health and Medical Research Council of Australia and the Swiss National Science Foundation.

\section{References}

Boreham, P. F. L. (1981). Giardiasis surveillance-Queensland. Communicable Diseases Intelligence Bulletin, 81 (5), 2-5

Burke, J. A. (1975). Giardiasis in childhood. American fournal of Diseases of Childhood, 129, 1304-1310

Castor, S. B. \& Lindqvist, K. B. (1990). Canine giardiasis in Sweden: no evidence of infectivity to man. Transactions of the Royal Society of Tropical Medicine and Hygiene, 84, 249-250.

Deplazes, P., Gottstein, B., Eckert, I., Jenkins, D. J., Ewald, D. \& Jimenez-Placios, S. (1992). Detection of Echinococcus coproantigens by enzyme-linked immunosorbent assay in dogs, dingoes and foxes. Parasitology Research, in press.

Islam, A. (1990). Giardiasis in developing countries. In: Human Parasitic Diseases: Giardiasis, Meyer, E. A. (editor), vol. 3. Amsterdam: Elsevier, pp. 235-267.

Janoff, E. N., Craft, J. C., Pickering, L. K., Novotny, J., Blaser, M. J., Knisley, C. V. \& Reller, L. B. (1989). Diagnosis of Giardia lamblia infections by detection of parasitespecific antigens. Foumal of Clinical Microbiology, 27, $431-435$.

Meloni, B. P., Lymbery, A. J., Thompson, R. C. A. \& Gracey, M. (1988). High prevalence of Giardia lamblia in children from a WA Aboriginal community. Medical fournal of Australia, 149, 715 .

Meloni, B. P., Lymbery, A. J. \& Thompson, R. C. A. (1989). Characterization of Giardia isolates using a non-radiolabelled DNA probe, and correlation with the results of isoenzyme analysis. American fournal of Tropical Medicine and Hygiene, 40, 629-637.

Meyer, E. A. (1985). The epidemiology of giardiasis. Parasitology Today, 1, 101-105.

Nash, T. E., Herrington, D. A \& Levine, M. M. (1987) Usefulness of an enzyme-linked immunosorbent assay for detection of Giardia antigen in faeces. Fournal of Clinical Microbiology, 25, 1169-1171.

Rosoff, J. D., Sanders, C. A., Sonnad, S. S., De Lay, P. R. Hadley, W. K., Vincenzi, F. F., Yaiko, D. M. \& O'Hanley, P. D. (1989). Stool diagnosis of giardiasis using a commercially available enzyme immunoassay to detect Giurdiu-specific antigen 65 (GSA 65). Journal of Clinical Microbiology, 27, 1997-2002.

Swan, J. M. \& Thompson, R. C. A. (1986). The prevalence of Giardia in dogs and cats in Perth, Western Australia. Australian Veterinary fournal, 63, 110-112.

Taminelli, V., Eckert, J., Sydler, T., Gottstein, B., Corboz, L. \& Hofmann, M. (1989). Experimentelle Infektion von Kälbern und Schafen mit bovinen Giardia-Isolaten. Schweizer Archiv für Tierheilkunde, 131, 551-564.

Thompson, R. C. A. (1992). Parasitic zoonoses: problems created by people not animals. International Fournal for Parasito$\log y, 22,555-562$

Ungar, B. L. P., Yolken, R. E., Nash, T. E. \& Quinn, T. C. (1984). Enzyme-linked immunosorbent assay for the detection of Giardia lamblia in faecal specimens. Fournal of Infectious Diseases, 149, 90-97.

Vinayak, V. K., Dutt, P. \& Puri, M. (1991). An immunoenzymatic dot-ELISA for the detection of Giardia lamblia antigen in stool eluates of clinical cases of giardiasis. Fournal of Immunological Methods, 137, 245-251.

Wolfe, M. S. (1978). Giardiasis. New England fournal of Medicine, 298, 319-321.

Received 17 March 1992; revised 13 May 1992; accepted for publication 14 May 1992 